\title{
Contraceptive Utilisation Among Mothers of Reproductive Age in Ajman, United Arab Emirates
}

"Naila Kanwal, ${ }^{1}$ Jayakumary Muttappallymyalil, ${ }^{1}$ Shatha Al-Sharbatti, ${ }^{1}$ Iman Ismail ${ }^{2}$

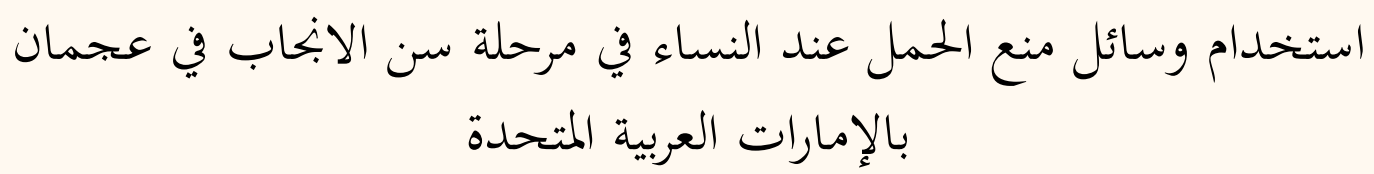

نائلة كنوال، جياكوماري موتابليمايليل، شذى الثرباتي، إيمان إسماعيل

ABSTRACT: Objectives: This study aimed to determine contraceptive utilisation among mothers aged 18-49 years old in Ajman, United Arab Emirates (UAE). Methods: This cross-sectional study was carried out from May to November 2013. A total of 400 participants were recruited from two primary healthcare centres and one private hospital in Ajman. An interviewer-administered validated questionnaire was used for data collection. Results: The frequency of previous and current contraceptive use was $68.0 \%$ and $61.8 \%$, respectively. Expatriates more frequently used contraceptives in comparison to Emiratis ( $77.3 \%$ versus $54.3 \%$, respectively). Contraceptive use increased significantly with age $(75.5 \%$ among $>35$-year-olds versus $57.3 \%$ among $\leq 25$-year-olds; $P<0.050)$ and education level $(83.3 \%$ among postgraduates versus $60.0 \%$ among those with primary education; $P<0.050)$. In addition, contraceptive use was significantly higher among those living in a nuclear family system $(P<0.050)$. A univariate analysis indicated significant associations between contraceptive use and age, nationality, education level, type of family system, employment sector, parity, knowledge of birth control measures and source of birth control information $(P<0.050$ each). However, no significant associations were found via multivariate analysis. Conclusion: Healthcare practitioners can play a pivotal role in providing contraceptive advice which could lead to an improvement in contraceptive utilisation. Efforts are recommended to raise awareness regarding newer forms of contraceptives among mothers of reproductive age in the UAE.

Keywords: Contraception; Family Planning Services; Reproductive Health; Women; United Arab Emirates.

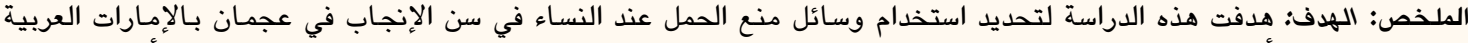

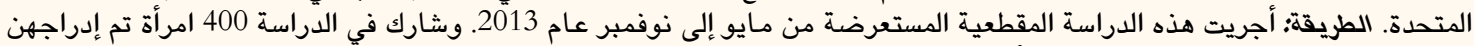

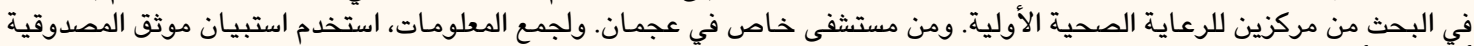

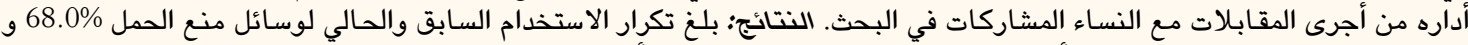

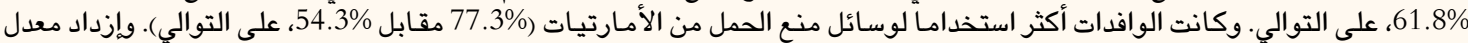

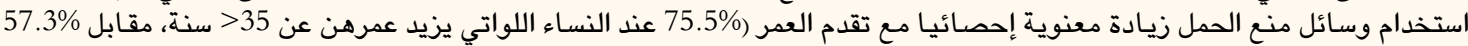

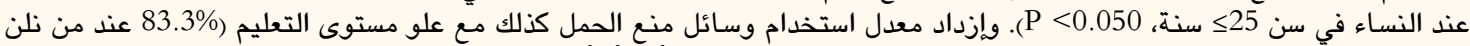

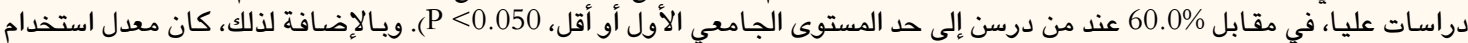

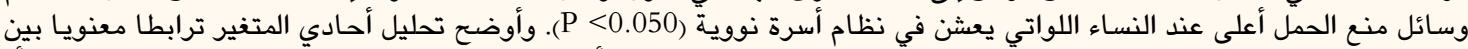

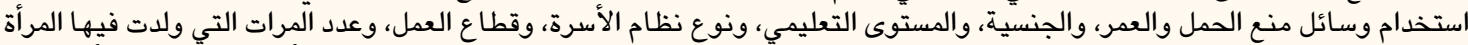

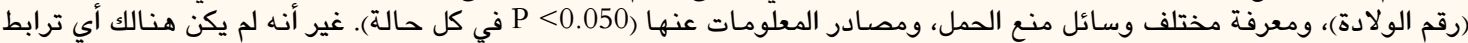

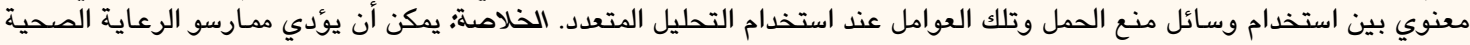

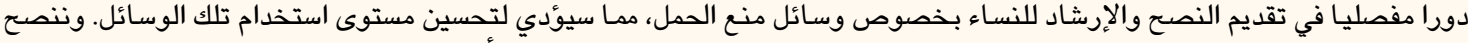

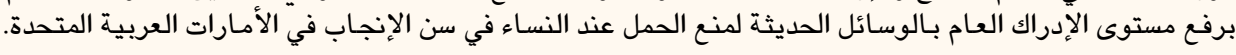

$$
\text { الكلمات المفتاحية: منع الحمل؛ خدمات تنظيم الأسرة؛ الصحة الإنجابية؛ النساء؛ الإمارات العربية المتحدة. }
$$

\section{Advances in KNOWLEDGE}

To the best of the authors' knowledge, the current study is one of the first in the United Arab Emirates (UAE) to carry out extensive research on contraceptive utilisation.

Among married mothers of reproductive age in Ajman, UAE, contraceptive use was significantly affected by various factors, including age, nationality, education level, type of family system and source of birth control information.

\section{Application to Patient Care}

The findings of the current study indicate that there is a need to increase awareness of contraceptive availability and options among women of reproductive age in the UAE, perhaps via appropriate community outreach awareness campaigns led by healthcare practitioners. 
A TIME PERIOD OF TWO YEARS IS RECOMMended between births to prevent adverse pregnancy outcomes and to aid optimal child growth. ${ }^{1}$ Contraceptives are family planning methods which can help individuals to control the timing, birth spacing and number of children they have, as necessary. ${ }^{1}$ Different methods of contraception exist with various benefits and drawbacks to each; an ideal contraceptive method is considered safe, effective, non-permanent, easy to use and affordable. ${ }^{2-4}$ Recently, high-quality family welfare programmes have been established in order to make contraception available, accessible, affordable and acceptable.,6 At the World Summit of 2005, various countries pledged their commitment to achieving universal access to reproductive healthcare by 2015; however, these goals are still far from being fully realised, with an estimated 143 million women worldwide still lacking access to contraception. ${ }^{7}$ Population growth rates in less developed countries are greater than those of more developed countries, due in part to a lack of access to reproductive healthcare services. ${ }^{2}$

Between 1970 and 2000, the worldwide fertility rate dropped from 4.7 to 2.6; this rapid decrease has been attributed to increased contraceptive usage in recent years. ${ }^{8}$ In 2011, it was estimated that $63 \%$ of women of reproductive age worldwide used various family planning methods. ${ }^{7}$ However, even in the USA, approximately $10-15 \%$ of all sexually active women do not use contraceptive measures, contributing to an unintentional pregnancy rate of $\approx 50 \%{ }^{2,9}$ A total of 830 women worldwide still die every day due to pregnancy-related complications; moreover, the risk of maternal mortality increases with each successive pregnancy and shorter intervals between births. ${ }^{10-12}$ As such, failures in adequate family planning measures can adversely affect the health of the mother and family as a whole. ${ }^{1,13}$

In the United Arab Emirates (UAE), considerable improvements have been made with regards to the availability of contraceptive measures in both public and private sectors in response to growing consumer demand. ${ }^{14}$ In 1995, the estimated prevalence of contraceptive use in the UAE among married women between 15-49 years old was 27.5\%. ${ }^{7}$ Other studies have reported rates of contraception use of $41.5 \%$ and $27 \%$ in 2001 and 2002, respectively. ${ }^{15,16}$ Unfortunately, there are no recent empirical studies on contraceptive utilisation in the UAE and previous findings are complicated by the existence of a diverse and multicultural society in which contraceptive use differs between population groups. This study therefore aimed to determine contraceptive utilisation among mothers of reproductive age in Ajman, UAE.

\section{Methods}

This cross-sectional study was carried out from May to November 2013 at two primary healthcare centres and one private hospital in Ajman. These locations were chosen so that the study participants would represent the diverse population of the UAE, as primary health care centres generally cater to the local Emirati population while expatriates typically seek healthcare services from private hospitals. The inclusion criteria consisted of married women between 18-49 years old who had given birth to at least one child previously, as women were considered less likely to use contraceptive measures immediately after marriage. Women who were currently pregnant, had previously undergone a hysterectomy or who could not comprehend the questions were excluded. For this study, as contraceptive prevalence varies among different ethnicities, a contraceptive utilisation prevalence of $50 \%$ was assumed with a marginal error of $5 \%$, resulting in a minimum required sample size of $400 . .^{15}$ As such, a total of 400 participants were recruited via a convenience sampling method from the Department of Obstetrics \& Gynaecology and the Paediatric \& Immunization Clinic of the GMC Hospital and the female outpatient departments of the Al Madina Primary Health Care Centre and Al Mushrif Primary Health Care Centre.

An interviewer-administered questionnaire was developed to collect information from the participants regarding their demographic characteristics (age, nationality, education level and duration of marriage), socioeconomic characteristics (employment status and sector as well as monthly income and type of family), reproductive history (number of pregnancies, live births and miscarriages) and contraceptive utilisation (current/previous use of contraceptives and preferred method of contraception). The questionnaire was originally developed in English before being translated into Arabic using back translation methods. For the purposes of the study, current contraceptive utilisation was defined as the use of any modern or traditional method to delay or avoid pregnancy within the preceding 30 days. ${ }^{17}$ This period was chosen to minimise recall bias. The use of contraception more than one month beforehand was considered to denote previous use. Family systems were categorised as either nuclear (i.e. a father, mother and their unmarried children), joint (i.e. a father, mother and their married sons or daughters, respective daughters-in-law or sons-in-law and any grandchildren in the same household) or threegeneration (i.e. a father, mother, only one married daughter or son, their respective daughter-in-law or son-in-law and their children) systems. 
Table 1: Sociodemographic characteristics of a cohort of married mothers of reproductive age in Ajman, United Arab Emirates $(\mathrm{N}=400)$

\begin{tabular}{|c|c|}
\hline Characteristic & n (\%) \\
\hline \multicolumn{2}{|l|}{ Age in years } \\
\hline$\leq 25$ & $75(18.8)$ \\
\hline$>25-35$ & $227(56.8)$ \\
\hline$>35$ & $98(24.5)$ \\
\hline \multicolumn{2}{|l|}{ Nationality } \\
\hline Emirati & $162(40.5)$ \\
\hline Non-Emirati & $238(59.5)$ \\
\hline \multicolumn{2}{|l|}{ Education level } \\
\hline Primary & $45(11.3)$ \\
\hline Secondary & $146(36.5)$ \\
\hline Graduate & $173(43.3)$ \\
\hline Postgraduate & $36(9.0)$ \\
\hline \multicolumn{2}{|c|}{ Employment status } \\
\hline Employed & $104(26.0)$ \\
\hline Unemployed & $296(74.0)$ \\
\hline \multicolumn{2}{|c|}{ Type of family system } \\
\hline Nuclear & $281(70.3)$ \\
\hline Joint & $69(17.3)$ \\
\hline Three-generation & $50(12.5)$ \\
\hline \multicolumn{2}{|c|}{ Number of children } \\
\hline 1 & $75(18.8)$ \\
\hline 2 & $165(41.3)$ \\
\hline 3 & $59(14.8)$ \\
\hline 4 & $44(11.0)$ \\
\hline 5 & $24(6.0)$ \\
\hline$\geq 6$ & $33(8.3)$ \\
\hline \multicolumn{2}{|c|}{ Current contraceptive use } \\
\hline Yes & $247(61.8)$ \\
\hline No & $153(38.3)$ \\
\hline \multicolumn{2}{|c|}{ Previous contraceptive use $^{\dagger}$} \\
\hline Yes & $272(68.0)$ \\
\hline No & $128(32.0)$ \\
\hline
\end{tabular}

In addition, the questionnaire also included items designed to assess factors influencing choice of contraceptive method (e.g. satisfaction with current contraceptive method, perceived vulnerability of becoming pregnant, concerns about side-effects, economic considerations, comfort with and access to contraceptives and associated embarrassment in discussing/buying contraceptives), reasons for using contraceptives (e.g. limiting family size, spacing pregnancies, financial or medical concerns, complications during previous pregnancies, genetic defects in older children and a desire to work outside of the home) and factors influencing discontinuation of birth control (e.g. hazards to health, refusal of the husband to cooperate in contraceptive use, secondary infertility, side-effects, cultural reasons, medical concerns and pressure from other family members not to use contraception). Knowledge of birth control measures was assessed by whether the participants knew about the existence of different contraceptives and, if so, the source of their information regarding contraceptives. The content validity of the questionnaire was assessed by public health experts and a gynaecologist. A pilot study was subsequently carried out to finalise the questionnaire items, assess the time needed to complete the questionnaire and determine whether participants could easily understand the questions. As a result, questions regarding husbands' age, education level and employment status were removed and a question assessing type of family system was included. The pilot study sample included five women recruited from the same study locations and using the same inclusion criteria as previously described; these women were not subsequently included in the full study.

Data were entered into a Microsoft Excel spreadsheet, Version 2007 (Microsoft Corp., Redmond, Washington, USA) and transferred for analysis to the Statistical Package for the Social Sciences (SPSS), Version 20 (IBM Corp., Chicago, Illinois, USA). Descriptive statistics, including frequencies and percentages, were used to describe the characteristics of the study population. A Chi-squared test was used to assess associations between independent and dependent variables. Significant variables were subsequently included in univariate and multivariate analyses. A $P$ value of $<0.050$ was considered statistically significant.

This study received ethical approval from the Ethics \& Research Committees of the Gulf Medical University, Ajman, and the UAE Ministry of Health (\#57/2013-06-27). All of the women gave written informed consent before participating in the study. Participants were assured of their anonymity and were informed that their responses would be kept confidential and used only for research purposes. 


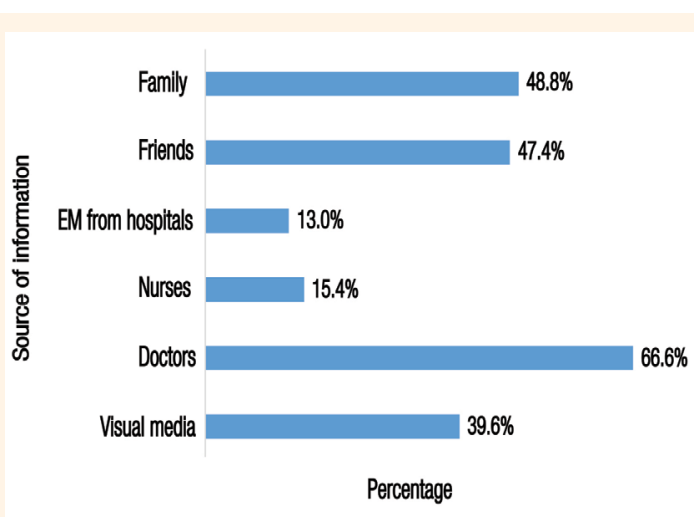

Figure 1: Sources of contraceptive information among a cohort of married mothers of reproductive age in Ajman, United Arab Emirates ( $\mathrm{N}=293)$.

$E M=$ educational material.

Table 2: Type of contraceptive used and preferred contraceptive method among current contraceptive

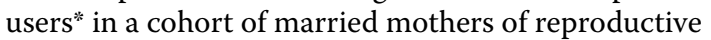
age in Ajman, United Arab Emirates ( $\mathrm{N}=247)$

\begin{tabular}{|c|c|}
\hline Variable & n (\%) \\
\hline \multicolumn{2}{|l|}{ Type of contraceptive used } \\
\hline Traditional $^{\dagger}$ & $83(33.6)$ \\
\hline Modern $^{\ddagger}$ & $164(66.4)$ \\
\hline \multicolumn{2}{|l|}{ Preferred contraceptive method } \\
\hline Male condoms & $78(31.6)$ \\
\hline IUD & $55(22.3)$ \\
\hline Withdrawal method & $50(20.2)$ \\
\hline Barrier and withdrawal method & $3(1.2)$ \\
\hline Hormone injection & $9(3.6)$ \\
\hline OCP & $40(16.2)$ \\
\hline Rhythm method & $3(1.2)$ \\
\hline Tubal ligation & $9(3.6)$ \\
\hline \multicolumn{2}{|c|}{$\begin{array}{l}\text { IUD = intrauterine device; OCP = oral contraceptive pill. } \\
\text { "Defined as contraceptive use within the previous } 30 \text { days. } \\
\text { 'Including the withdrawal and rhythm methods. }\end{array}$} \\
\hline
\end{tabular}

\section{Results}

The mean age of the participants was $31.57 \pm 6.88$ years (range: 18-49 years old). The majority of the participants were $25-35$ years old (56.8\%), expatriates (59.5\%), had a graduate level of education or higher (52.3\%), were unemployed (74.0\%), lived in a nuclear family system (70.3\%) and had two children (41.3\%). In terms of current contraceptive use, a total of 247 participants (61.8\%) were current contraceptive
Table 3: Relationships between previous contraceptive use $^{*}$ and sociodemographic characteristics and source of contraceptive information in a cohort of married mothers of reproductive age in Ajman, United Arab Emirates $(\mathrm{N}=400)$

\begin{tabular}{|c|c|c|c|}
\hline \multirow[t]{2}{*}{ Characteristic } & \multicolumn{2}{|c|}{ n (\%) } & \multirow[t]{2}{*}{$P$ value } \\
\hline & $\begin{array}{c}\text { Previous } \\
\text { contraceptive } \\
\text { use } \\
(\mathbf{n}=272)\end{array}$ & $\begin{array}{l}\text { No previous } \\
\text { contraceptive } \\
\text { use } \\
(\mathbf{n}=\mathbf{1 2 8})\end{array}$ & \\
\hline \multicolumn{3}{|l|}{ Age in years } & \multirow{4}{*}{$<0.050$} \\
\hline$\leq 25$ & $43(57.3)$ & $32(42.7)$ & \\
\hline$>25-35$ & $155(68.3)$ & $72(31.7)$ & \\
\hline$>35$ & $74(75.5)$ & $24(24.5)$ & \\
\hline \multicolumn{3}{|l|}{ Nationality } & \multirow{3}{*}{$<0.001$} \\
\hline Emirati & $88(54.3)$ & $74(45.7)$ & \\
\hline Non-Emirati & $184(77.3)$ & $54(22.7)$ & \\
\hline \multicolumn{3}{|l|}{ Education level } & \multirow{5}{*}{$<0.050$} \\
\hline Primary & $27(60.0)$ & $18(40.0)$ & \\
\hline Secondary & $89(61.0)$ & $57(39.0)$ & \\
\hline Graduate & $126(72.8)$ & $47(27.2)$ & \\
\hline Postgraduate & $30(83.3)$ & $6(16.7)$ & \\
\hline \multicolumn{3}{|c|}{ Employment status } & \multirow{3}{*}{0.075} \\
\hline Employed & $78(75.0)$ & $26(25.0)$ & \\
\hline Unemployed & $194(65.5)$ & $102(34.5)$ & \\
\hline \multicolumn{3}{|c|}{ Type of family system } & \multirow{5}{*}{$<0.050$} \\
\hline Nuclear & $203(72.2)$ & $78(27.8)$ & \\
\hline Joint & $43(62.3)$ & $26(37.7)$ & \\
\hline Three-generation & $26(52.0)$ & $24(48.0)$ & \\
\hline \multicolumn{3}{|c|}{ Number of children } & \\
\hline 1 & $35(46.7)$ & $40(53.3)$ & \multirow{6}{*}{$<0.010$} \\
\hline 2 & $117(70.9)$ & $48(29.1)$ & \\
\hline 3 & $46(78.0)$ & $13(22.0)$ & \\
\hline 4 & $33(75.0)$ & $11(25.0)$ & \\
\hline 5 & $18(75.0)$ & $6(25.0)$ & \\
\hline$\geq 6$ & $23(69.7)$ & $10(30.3)$ & \\
\hline
\end{tabular}

*Defined as contraceptive use before the preceding 30 days.

users, while 153 (38.2\%) had not used any method of contraception within the previous 30 days. A total of 272 women $(68.0 \%)$ had previously used contraceptives before the preceding 30 days while 128 (32.0\%) had never used contraceptives [Table 1].

Among previous contraceptive users, decisions relating to contraceptive choice ( $\mathrm{n}=141 ; 51.8 \%$ ) 
Table 4: Relationships between previous contraceptive use" and source of contraceptive information in a cohort of married mothers of reproductive age in Ajman, United Arab Emirates $(\mathrm{N}=293)$

\begin{tabular}{|c|c|c|c|}
\hline \multirow{2}{*}{ Source } & \multicolumn{2}{|c|}{ n (\%) } & \multirow[t]{2}{*}{$P$ value } \\
\hline & $\begin{array}{c}\text { Previous } \\
\text { contraceptive } \\
\text { use }(n=262)\end{array}$ & $\begin{array}{l}\text { No previous } \\
\text { contraceptive } \\
\text { use }(\mathbf{n}=31)\end{array}$ & \\
\hline \multicolumn{3}{|c|}{ Visual media } & 0.148 \\
\hline Yes & $100(38.2)$ & 16 (51.6) & \\
\hline No & $162(61.8)$ & 15 (48.4) & \\
\hline \multicolumn{3}{|l|}{ Doctors } & $<0.050$ \\
\hline Yes & $180(68.7)$ & $15(48.4)$ & \\
\hline No & $82(31.3)$ & $16(51.6)$ & \\
\hline \multicolumn{3}{|l|}{ Nurses } & 0.900 \\
\hline Yes & $40(15.3)$ & $5(16.1)$ & \\
\hline No & $222(84.7)$ & $26(83.9)$ & \\
\hline \multicolumn{3}{|c|}{ EM from hospitals } & 0.263 \\
\hline Yes & $32(12.2)$ & $6(19.4)$ & \\
\hline No & $230(87.8)$ & $25(80.6)$ & \\
\hline \multicolumn{3}{|l|}{ Friends } & 0.911 \\
\hline Yes & $124(47.3)$ & $15(48.4)$ & \\
\hline No & $138(52.7)$ & $16(51.6)$ & \\
\hline \multicolumn{3}{|l|}{ Family } & 0.477 \\
\hline Yes & $126(48.1)$ & $17(54.8)$ & \\
\hline No & $136(51.9)$ & $14(45.2)$ & \\
\hline
\end{tabular}

and duration of use $(\mathrm{n}=182 ; 66.9 \%)$ were most commonly made by both partners. When asked about their knowledge of birth control measures, 293 women $(73.3 \%)$ knew about contraceptives, with doctors being reported as the most common source of contraceptive information (66.6\%) [Figure 1]. The majority of the participants $(66.4 \%)$ used modern contraceptive methods, for instance male condoms, intrauterine devices (IUDs), oral contraceptive pills or tubal ligation. Fewer participants (33.6\%) employed traditional contraceptive measures, such as the withdrawal or rhythm methods (i.e. engaging in sexual intercourse only during 'safe' non-ovulation periods). Male condom use was reported to be the most commonly preferred method of contraception (31.6\%) [Table 2].

The use of contraceptives was significantly higher among expatriates in comparison to Emiratis (77.3\% versus $54.3 \% ; P<0.001)$. Contraceptive use also increased significantly with age $(75.5 \%$ among
Table 5: Univariate analysis of relationships between significant variables and previous contraceptive use ${ }^{*}$ in a cohort of married mothers of reproductive age in Ajman, United Arab Emirates $(\mathrm{N}=272)$

\begin{tabular}{|c|c|c|}
\hline Variable & OR (CI) & $P$ value \\
\hline \multicolumn{3}{|l|}{ Age in years } \\
\hline$\leq 25$ & 1 & - \\
\hline$>25-35$ & $0.62(0.37-1.07)$ & 0.085 \\
\hline$>35$ & $0.44(0.23-0.83)$ & $<0.050$ \\
\hline \multicolumn{3}{|l|}{ Nationality } \\
\hline Non-Emirati & 1 & - \\
\hline Emirati & $2.87(1.86-4.42)$ & $<0.001$ \\
\hline \multicolumn{3}{|l|}{ Education level } \\
\hline Postgraduate & 1 & - \\
\hline Primary & $3.33(1.16-9.62)$ & $<0.050$ \\
\hline Secondary & $3.20(1.25-8.18)$ & $<0.050$ \\
\hline Graduate & $1.87(0.73-4.77)$ & 0.191 \\
\hline \multicolumn{3}{|c|}{ Type of family system } \\
\hline Nuclear & 1 & - \\
\hline Joint & $1.57(0.90-2.73)$ & 0.103 \\
\hline Three-generation & $2.40(1.30-4.43)$ & $<0.010$ \\
\hline \multicolumn{3}{|c|}{ Employment sector } \\
\hline Private & 1 & - \\
\hline Government & $4.89(1.90-12.56)$ & $<0.001$ \\
\hline \multicolumn{3}{|c|}{ Number of children } \\
\hline$\geq 6$ & 1 & - \\
\hline 1 & $2.63(1.10-6.27)$ & $<0.050$ \\
\hline 2 & $0.94(0.42-2.13)$ & 0.891 \\
\hline 3 & $0.65(0.25-1.70)$ & 0.378 \\
\hline 4 & $0.77(0.28-2.10)$ & 0.599 \\
\hline 5 & $0.77(0.23-2.50)$ & 0.661 \\
\hline
\end{tabular}

Knowledge of birth control measures

No

1

Yes

$0.01(0.01-0.03)$

$<0.001$

Doctors as source of contraceptive information

No

Yes

$0.43(0.20-0.91)$

$<0.050$

$O R=$ odds ratio; $C I=$ confidence interval

"Defined as contraceptive use before the preceding 30 days.

$>35$-year-olds versus $57.3 \%$ among $\leq 25$-year-olds; $P<0.050)$, education level $(83.3 \%$ among postgraduates versus $60.0 \%$ among women with primary education only; $P<0.050)$ and family system $(72.2 \%$ 
Table 6: Multivariate analysis of relationships between significant variables and previous contraceptive use* in a cohort of married mothers of reproductive age in Ajman, United Arab Emirates $(\mathrm{N}=272)$

\begin{tabular}{|c|c|c|}
\hline Variables & OR (CI) & $P$ value \\
\hline \multicolumn{3}{|l|}{ Age in years } \\
\hline$\leq 25$ & 1 & - \\
\hline$>25-35$ & $0.09(0.00-4.88)$ & 0.242 \\
\hline$>35$ & $0.19(0.00-10.15)$ & 0.421 \\
\hline \multicolumn{3}{|l|}{ Nationality } \\
\hline Non-Emirati & 1 & - \\
\hline Emirati & $0.05(0.00-7.93)$ & 0.243 \\
\hline \multicolumn{3}{|l|}{ Education level } \\
\hline Postgraduate & 1 & - \\
\hline Primary & 0.00 & $>0.999$ \\
\hline Secondary & 0.00 & 0.994 \\
\hline Graduate & $0.05(0.00-3.89)$ & 0.184 \\
\hline \multicolumn{3}{|c|}{ Type of family system } \\
\hline Nuclear & 1 & - \\
\hline Joint & $134.77(0.62-1,942.37)$ & 0.083 \\
\hline Three-generation & 0.00 & 0.993 \\
\hline \multicolumn{3}{|c|}{ Employment sector } \\
\hline Private & 1 & - \\
\hline Government & $2.07(0.14-30.97)$ & 0.588 \\
\hline \multicolumn{3}{|c|}{ Number of children } \\
\hline$\geq 6$ & 1 & - \\
\hline 1 & 0.00 & $>0.999$ \\
\hline 2 & $4,885.08$ & $>0.999$ \\
\hline 3 & 0.00 & $>0.999$ \\
\hline 4 & 0.00 & $>0.999$ \\
\hline 5 & 0.00 & 0.994 \\
\hline \multicolumn{3}{|c|}{ Knowledge of birth control measures } \\
\hline No & 1 & - \\
\hline Yes & $0.15(0.01-3.96)$ & 0.258 \\
\hline \multicolumn{3}{|c|}{ Doctors as source of contraceptive information } \\
\hline No & 1 & - \\
\hline Yes & 96.71 & 0.333 \\
\hline
\end{tabular}

among women with nuclear families versus $62.3 \%$ among those with joint families and $52.0 \%$ among those with three-generation families; $P<0.050)$. A sta- tistically significant positive association was observed between number of children and the use of contraceptives $(P<0.010)$. Employment status was not significantly associated with the use of contraceptives [Table 3]. In terms of associations between source of contraceptive knowledge and use of contraception, doctors were the only information source which showed a significant association with contraceptive use $(P<0.050)$ [Table 4].

A univariate analysis was conducted to determine factors affecting the probability of not using contraception. Among women $>35$ years of age, there was a $56 \%$ lower chance of not using contraceptives in comparison to those $\leq 25$ years old (odds ratio [OR]: 0.44, confidence interval [CI]: 0.23-0.83). Among Emiratis, the likelihood of not using contraceptives was three times higher than for expatriates (OR: 2.87, CI: 1.86-4.42). Women with primarylevel education were three times more likely not to use contraception in comparison to postgraduates (OR: 3.33, CI: 1.16-9.62). Similarly, among women with a secondary education, the likelihood of not using contraceptives was 3.2 times higher compared to postgraduates (OR: 3.20, CI: 1. 25-8.18). Women from a three-generation family system had a 2.4 times higher chance of not using contraception compared to those with a nuclear family system (OR: 2.40, CI: 1.30-4.43). Working in the government sector resulted in a five times increased chance of not using contraceptives compared to the private sector (OR: 4.89, CI: 1.90-12.56). Women with one child were 2.6 times more likely to not use contraception as compared to those with $\geq 6$ children (OR: 2.63, CI: 1.10-6.27). Women who knew about birth control measures were $99 \%$ more likely to use contraceptives (OR: 0.01, CI: 0.01-0.03). Among participants whose primary source of information about contraceptives was doctors, there was a 57\% lower chance of not using contraceptives (OR: 0.43, CI: 0.20-0.91) [Table 5]. However, none of these variables were significantly associated with contraceptive use according to a multivariate analysis [Table 6].

\section{Discussion}

Preventing an unplanned pregnancy is an important global issue. ${ }^{17}$ Effective contraceptives benefit both mothers and their children by decreasing morbidity and mortality rates and improving their social and economic status. ${ }^{18}$ In the UAE, there is high parity and social acceptance of birth control is limited for cultural and religious reasons. ${ }^{15}$ The current study aimed to determine contraceptive utilisation among mothers 
of reproductive age in Ajman. According to the 2005 census, the total number of women of reproductive age in Ajman was 47,191; of these, 10,687 were Emiratis (22.6\%) and 36,504 were expatriates (77.4\%). ${ }^{19}$

Rates of contraceptive use vary in Arab countries. In the current study, the current and previous use of contraceptives was found to be $61.8 \%$ and $68.0 \%$, respectively. Use of contraceptives was noted to be $44.8 \%$ and $47.8 \%$ in Saudi Arabia and Qatar, respectively. ${ }^{20,21}$ Higher rates have been observed in Bahrain (61.8\%), Syria (58.3\%) and Lebanon (58\%), while lower rates have been reported from Qatar (43.2\%), Oman (31.7\%), Yemen (27.7\%) and Saudi Arabia (23.8\%). ${ }^{7}$ This variation in findings could be attributed to differences in local cultural attitudes in these countries towards the use of contraceptives. In the current study, previous use of contraceptives was higher among expatriates than Emiratis and the probability of not using contraceptives was three times higher among Emiratis; this rate was higher than that reported in previous research. ${ }^{15}$

Age was found to have a significant relationship with contraceptive use in the current study, with older women more likely to use contraceptives in comparison to younger women. This observation is in accordance with previous research conducted in Saudi Arabia and Qatar. ${ }^{20,21}$ This finding may be due to the fact that older women are more likely to use contraceptives if their fertility goals have already been met or to ensure a greater amount of time between births to preserve their health. Among women under 25 years old, contraceptive use was less frequent; this might be explained by an increased desire to have more children, as noted in previous studies conducted in the UAE and Saudi Arabia. ${ }^{15,20}$ In addition, the current study found that contraceptive use increased with education level; this finding is similar to that of previous research conducted in the Gulf region..$^{15,20,21}$ However, studies conducted in India have found that education was not associated positively with contraceptive use..$^{22,23}$ In general, improving women's education has been reported as a method of increasing their status and autonomy, which in turn can help to improve contraceptive practices. ${ }^{24}$ It is possible that less educated women have fewer educational and career-oriented aspirations and have lower levels of understanding of their health as compared to more educated women. ${ }^{25}$

Employment status and contraceptive use were not found to be significantly associated in the present study. This is contrary to findings from Saudi Arabia, where contraceptive use was reportedly four times higher among working women. ${ }^{20}$ However, mothers working in the private sector in the current study were five times more likely to use contraceptives compared to government sector workers. This may be because employment decisions among mothers often depend on family and child care responsibilities; as such, women may prefer government professions over those in the private sector due to increased job and income security, more desirable working conditions and shorter working hours. ${ }^{26}$ A significant association between type of family system and use of contraceptives was noted in the current study. Women within a three-generation family system were less likely to use contraceptives compared to those within a nuclear family system. Evidence from Pakistan and India suggests that a joint family system may influence unsupportive or restrictive attitudes towards contraceptives. ${ }^{27-29}$ In addition, individuals in a joint family system often depend financially on the head of the family and therefore may not be limited by financial concerns when making family planning decisions. $^{29}$ Moreover, in a joint family system, a woman's social position can be elevated after the birth of a child and they may not be solely responsible for making the decision to have more children. ${ }^{29}$ In general, most women prefer to use contraceptives after they have reached their ideal family size..$^{20,30}$ However, the ideal family size differs according to culture and society. In the current study, women with one child were less likely to use contraception compared to those with six children or more. This finding is consistent with previous research from Saudi Arabia, which has similar religious and cultural characteristics to the UAE; contraceptive usage was reportedly to be higher among women with higher parity. ${ }^{20}$

The majority of participants in the current study were aware of birth control measures; in addition, knowledge of birth control measures was significantly associated with contraceptive use. In contrast, research conducted in Qatar indicated that the majority of participants were aware of contraceptives but had a negative attitude towards contraceptive use due to their sociocultural norms and religious beliefs. ${ }^{21}$ In Saudi Arabia and Qatar, family members and friends were found to be the most common source of contraceptive information. ${ }^{20,21}$ However, in the current study, doctors were reported to be the main source of information about contraceptives; moreover, mothers who reported doctors as a source of contraceptive information had an increased probability of using contraceptives as compared to those who did not. This observation is in line with previously reported research in the region. ${ }^{15}$ This result clearly demonstrates the importance of doctors in providing advice to women about contra- 
ceptives and influencing decisions to use contraceptives. Therefore, sustained efforts to raise awareness of the proper use of contraceptives is highly recommended in the UAE, for instance through the implementation of doctor-led community outreach/ awareness campaigns.

In the present study, women who were currently using contraceptives primarily used modern methods of contraception. This is a key finding as previous research in the UAE reported a greater frequency of use of traditional contraceptive methods, followed by the IUD. ${ }^{15}$ However, the current study's results were in accordance with research from Qatar, where the practice of modern contraceptive methods was higher among current contraceptive users, probably due to the influence of economic development and the increased availability of information. ${ }^{21}$ In the current study, the most preferred birth control method was found to be male condoms followed by IUDs and the withdrawal method. Potentially, more women might prefer condoms as compared to other methods of contraception because of their easy availability without a prescription or due to concerns about the possible side-effects of other contraceptive methods. Few women in the current study were aware of newer forms of contraceptives (e.g. transdermal patches, implants and rings); as such there is an urgent need to increase awareness of contraceptive availability and options among women of reproductive age in the UAE.

The current study is subject to certain limitations. The findings are not generalisable to all women in the UAE due to the non-probability sampling method used to recruit participants. Moreover, as the participants were recruited from women attending primary healthcare centres and private hospitals in Ajman, the study cohort is not representative of the general population. In addition, the findings do not include contraceptive use among sexually-active single women as the aim of the study focused on contraceptive use among married women; however, it is important to note that extramarital relations are prohibited in predominantly Islamic countries, such as the UAE, and are henceforth not usually openly discussed. ${ }^{15}$ Further research is recommended in order to compare the findings of the current study to those of the general population in the UAE.

\section{Conclusion}

The rates of current and previous contraceptive use among a cohort of married mothers of reproductive age in Ajman were $61.8 \%$ and $68.0 \%$, respectively. Contraceptive use was higher among expatriates than Emiratis. Significant associations were observed between contraceptive use and age, nationality, education level, type of family system, employment sector, number of children, knowledge of birth control measures and source of contraceptive information. Doctors were noted to have an important influence on contraceptive use. Community outreach awareness campaigns on the availability and proper use of contraceptives are highly recommended.

\section{CONFLICT OF INTEREST}

The authors declare no conflicts of interest.

\section{FUNDING}

No funding was received for this study.

\section{References}

1. Shaw D. The ABC's of family planning. From: www.who. int/pmnch/media/news/2010/20100322_d_shaw_oped/en/ Accessed: Aug 2016

2. Sonalkar S, Schreiber CA, Barnhart KT. Contraception. In: De Groot LJ, Chrousos G, Dungan K, Feingold KR, Grossman A, Hershman JM, et al., Eds. From: www.ncbi.nlm.nih.gov/books/ NBK279148/ Accessed: Aug 2016.

3. World Health Organization. Family planning: Contraception Fact sheet. From: http://who.int/mediacentre/factsheets/fs 351/en/ Accessed: Aug 2016

4. World Health Organization. Family planning: A global handbook for providers - 2011 update. From: http://apps.who. int/iris/bitstream/10665/44028/1/9780978856373_eng.pdf Accessed: Aug 2016.

5. Cleland J, Bernstein S, Ezeh A, Faundes A, Glasier A, Innis J. Family planning: The unfinished agenda. Lancet 2006; 368: 1810-27. doi: 10.1016/S0140-6736(06)69480-4.

6. United Nations Population Fund. International Conference on Population and Development: Overview. From: www.unfpa. org/icpd Accessed: Aug 2016.

7. United Nations Department of Economic and Social Affairs. World contraceptive patterns 2013. From: www. un.org/en/development/desa/population/publications/ pdf/family/worldContraceptivePatternsWallChart2013.pdf Accessed: Aug 2016

8. Ahmed S, Li Q, Liu L, Tsui AO. Maternal deaths averted by contraceptive use: An analysis of 172 countries. Lancet 2012; 380:111-25. doi: 10.1016/S0140-6736(12)60478-4.

9. Bonham $\mathrm{AD}$. Why are 50 percent of pregnancies in the U.S. unplanned? From: http://shriverreport.org/why-are-50-perc ent-of-pregnancies-in-the-us-unplanned-adrienne-dbonham/ Accessed: Aug 2016.

10. World Health Organization. Maternal mortality: Fact sheet. From: www.who.int/mediacentre/factsheets/fs348/en/index.html Accessed: Aug 2016.

11. Lassi ZS, Middleton PF, Bhutta ZA, Crowther C. Strategies for improving health care seeking for maternal and newborn illnesses in low- and middle-income countries: A systematic review and meta-analysis. Glob Health Action 2016; 9:31408. doi: 10.3402/gha.v9.31408.

12. Smith R, Ashford L, Gribble J, Clifton D; Population Reference Bureau. Family planning saves lives, 4th ed. From: www.prb. org/pdf09/familyplanningsaveslives.pdf Accessed: Aug 2016. 
13. Leke RJ; Geneva Foundation for Medical Education and Research. Family planning in Africa south of the Sahara. From: www.gfmer.ch/Books/Reproductive_health/Family_planning_ Africa.html Accessed: Aug 2016.

14. United Nations Department of Economic and Social Affairs. United Arab Emirates: Abortion policy and reproductive health context. From: www.un.org/esa/population/publications/abor tion/doc/uae.doc Accessed: Aug 2016.

15. Ghazal-Aswad S, Rizk DE, Al-Khoori SM, Shaheen H, Thomas L. Knowledge and practice of contraception in United Arab Emirates women. J Fam Plann Reprod Health Care 2001; 27:212-16. doi: 10.1783/147118901101195786.

16. Ghazal-Aswad S, Zaib-Un-Nisa S, Rizk DE, Badrinath P, Shaheen H, Osman N. A study on the knowledge and practice of contraception among men in the United Arab Emirates. J Fam Plann Reprod Health Care 2002; 28:196-200. doi: $10.1783 / 147118902101196559$.

17. Sarah P. The attack on planned parenthood: A historical analysis. UCLA Womens Law J 2012; 19:165-211.

18. Kaunitz AM. The importance of contraception. From: www. glowm.com/section_view/heading/The\%20Importance $\% 20$ of\%20Contraception/item/373 Accessed: Aug 2016.

19. Judy Y. Population and Vital Statistics, 1st ed. Ajman, United Arab Emirates: Ajman Executive Council, 2008. Pp. 41-58.

20. Al Sheeha M. Awareness and use of contraceptives among Saudi women attending primary care centers in Al-Qassim, Saudi Arabia. Int J Health Sci (Qassim) 2010; 4:11-21.

21. Arbab AA, Bener A, Abdulmalik M. Prevalence, awareness and determinants of contraceptive use in Qatari women. East Mediterr Health J 2011; 17:11-18.
22. Pushpa S, Venkatesh R, Shivaswamy M. Study of fertility pattern and contraceptive practices in a rural area: A crosssectional study. Indian J Sci Technol 2011; 4:429-31.

23. Chudasama R, Godara N, Moitra M. Women's position and their behavior towards family planning. Internet J Fam Pract 2008; 7:1-5.

24. Saleem S, Bobak M. Women's autonomy, education and contraception use in Pakistan: A national study. Reprod Health 2005; 2:8. doi: 10.1186/1742-4755-2-8

25. Ong J, Temple-Smith M, Wong WC, McNamee K, Fairley C. Contraception matters: Indicators of poor usage of contraception in sexually active women attending family planning clinics in Victoria, Australia. BMC Public Health 2012; 12:1108. doi: 10.1186/1471-2458-12-1108.

26. Narcisse DA, State Y. Risky undertakings: The employment decision-making of women lawyers and accountants. Forum Qual Soc Res 2011; 12:3.

27. Kazi K. A study of knowledge, attitude and practice (KAP) of family planning among the women of rural Karachi. Thesis, 2008, University of Karachi, Karachi, Pakistan.

28. Fikree FF, Khan A, Kadir MM, Sajan F, Rahbar MH. What influences contraceptive use among young women in urban squatter settlements of Karachi, Pakistan? Int Fam Plan Perspect 2001; 27:130-6. doi: 10.2307/2673834.

29. Murarkar SK, Soundale S. Epidemiological correlates of contraceptive prevalence in married women of reproductive age group in rural area. Natl J Community Med 2011; 2:78-81.

30. Population Reference Bureau. Women's need for family planning in Arab countries. From: www.prb.org/Publications/ Reports/2012/family-planning-arab-countries.aspx Accessed: Aug 2016.

\section{GLOBAL DISTRIBUTION}

Print copies of each issue of SQUMJ are distributed to over 500 medical colleges all over the world, including Oman, the surrounding Eastern Mediterranean region, the UK, Australia, Canada and the USA. 